\title{
Sintomas da injúria por frio em Heliconia spp.(1)
}

\author{
GUSTAVO JONNAS S. M. BEZERRA (2); ANDRÉ LUIZ VERONA(3); RICARDO DE MENDONÇA MOTTA(2); \\ VIVIAN LOGES ${ }^{(3)}$; ANDREZA SANTOS DA $\operatorname{COSTA}^{(3)}$
}

\begin{abstract}
RESUMO
As helicônias, entre as flores tropicais, têm se destacado no mercado internacional (Europa e Estados Unidos) devido à beleza, diversidade de cores e formas e durabilidade. No entanto, para a comercialização a longas distâncias é necessário adotar formas de transporte que inibam o processo de senescência das flores e conservem a qualidade pós-colheita. $\mathrm{O}$ transporte de flores em temperaturas baixas é o mais utilizado, no entanto, em "flores tropicais" podem causar danos de injúria por frio. O objetivo deste trabalho foi descrever os sintomas causados pela injúria por frio em hastes florais de três genótipos de helicônia (H. bihai, $H$. wagneriana e $H$. caribaea $x H$. bihai cv. Carib Flame). As hastes florais de helicônia foram submetidas, por 72 horas, a três condições de temperatura: refrigerador expositor $\left(2{ }^{\circ} \mathrm{C}\right)$ em caixa de papelão (embalagem padrão para transporte); refrigerador expositor $\left(2{ }^{\circ} \mathrm{C}\right)$ sem caixa de papelão; e laboratório a $25^{\circ} \mathrm{C}$ e U.R. $60 \%$ (testemunha). O delineamento experimental utilizado foi o inteiramente casualizado, com três tratamentos e sete repetições na primeira avaliação e cinco repetições na segunda avaliação. Os sintomas da injúria por frio foram descritos a partir da comparação do aspecto visual das hastes florais submetidas a $2{ }^{\circ} \mathrm{C} \mathrm{com}$ as testemunhas. A temperatura de $2{ }^{\circ} \mathrm{C}$, com ou sem a embalagem de transporte, provocou sintomas como: aspecto de queimadura no centro das brácteas, manchas escurecidas na área de inserção das brácteas na ráquis e murchamento das extremidades dos pecíolos das folhas e da base das inflorescências.
\end{abstract}

Palavras-chave: flor de corte, pós-colheita, temperatura.

\section{ABSTRACT \\ Chilling symptoms in Heliconia spp.}

There is an increasing demand on the international market for Heliconia inflorescences, which are considered "tropical flowers", with attractive and lasting tropical beauty. Commercialization to long distance markets requires transportation in low temperatures in order to inhibit the flower senescence processes. However, low temperatures may cause chilling to the plant tissue. The objective of this experiment was to describe the chilling symptoms to the cut flowers of three different heliconia genotypes (Heliconia bihai, H. wagneriana and H. caribaea $\mathrm{x}$ H. bihai 'Carib Flame'). The experiment design was completely randomized design and three treatments, with seven replications for the first evaluation and five replications for the second evaluation. The heliconia cut flowers were exposed to three different treatments for 72 hours: control treatment (laboratory room temperature $25^{\circ} \mathrm{C}$ and relative humidity $60 \%$ ) and display refrigerator at 2 ${ }^{\circ} \mathrm{C}$, with and without cardboard box for transportation. The chilling symptoms were described comparing, through the refrigerator display, the treated flowering stems with the control treatment. The temperature of $2{ }^{\circ} \mathrm{C}$, with or without cardboard box, induced the following symptoms: burn aspect in the center of the bracts, dark spots on the insertion area of the bracts to the rachis, and wilting on the leaf petiole ends and on the inflorescence bases.

Key Words: cut flower, post harvest, temperature.

\section{INTRODUÇÃO}

Dentre flores de corte exploradas comercialmente, as tropicais têm adquirido importância econômica e comercial no mercado interno e externo pela beleza, colorido e aspecto exótico de suas inflorescências. Algumas espécies do gênero Heliconia se destacam na
Europa e nos Estados Unidos como flores de corte, sendo conhecidas como "flores tropicais", pelas quais consumidores pagam elevados preços (CASTRO e GRAZIANO, 1997).

As helicônias apresentam variação considerável quanto à durabilidade em vaso (CRILEY e BROSCHAT, 1992). Além das características intrínsecas das espécies

\footnotetext{
(1) Trabalho recebido para publicação em 29/06/2008 e aprovado em 05/05/2008.

(2) Empresa Pernambucana de Pesquisa Agropecuária (IPA), E-mail: gustavojonnas@ig.com.br; rcardomotta@hotmail.com

(3) Universidade Federal Rural de Pernambuco (UFRPE), E-mail: gauchoufrpe@gmail.com; vloges@yahoo.com; andreza.costa@gmail.com
} 
quanto à durabilidade pós-colheita das flores, o manejo pós-colheita é de decisiva importância para o sucesso da comercialização.

Tratamentos pós-colheita, transporte e armazenamento sob refrigeração podem estender a vida comercial, intensificar a absorção e o transporte de água, prevenir a perda de água das hastes florais (JAROENKIT e PAULL, 2003), além disso, diminui as infecções bacterianas e fúngicas e inibe os diferentes processos relativos ao desenvolvimento e senescência das flores. Assim, o armazenamento a frio (seco ou úmido) é o método mais utilizado para reduzir esses processos (MORAES et al., 1999), visando basicamente contornar os problemas de conservação, transporte e distribuição de flores. A exposição à temperatura inadequada por longos períodos é a maior causa de descarte na floricultura em geral (SONEGO e BRACKMANN, 1995) o que tem ocasionado elevados prejuízos aos produtores.

Alguns autores divergem quanto ao intervalo de temperatura mais apropriado para o armazenamento de flores originárias de clima tropical. JAROENKIT e PAULL (2003) recomendam temperaturas não inferiores a $10^{\circ} \mathrm{C}$ e ainda afirmam que flores tropicais de corte, diferentemente das flores temperadas de corte, são facilmente danificadas, quando transportadas em temperaturas abaixo do intervalo de 8 a $12^{\circ} \mathrm{C}$. LAMAS (2001) cita temperaturas não inferiores a $14^{\circ} \mathrm{C}$ e NOWAK e RUDNICKI (1990) indicam um intervalo compreendido entre 7 e $15^{\circ} \mathrm{C}$.

Temperaturas muito baixas e longos períodos de exposição podem causar alguns problemas de injúria por frio, como: murchamento de flores e hastes florais, necrose nos tecidos, manchas escuras ou pardas, descoloração de brácteas, aumento da suscetibilidade ao ataque de microrganismos, extravasamento hídrico dos tecidos e atraso da abertura de partes florais após armazenamento (MORAES et al., 1999; NOWAK e RUDNICKI, 1990). O murchamento e enrugamento da superfície dos órgãos vegetais são decorrentes da redução de peso, causada principalmente devido a perda de água durante a transpiração (FINGER e VIEIRA, 2002). Todos esses sintomas são depreciativos à beleza e qualidade das hastes florais e concorrem para a redução de seu valor comercial. Para evitar esse problema, recomenda-se a utilização de temperatura adequada para armazenamento e transporte do produto.

A gravidade dos sintomas causados pelo frio está relacionada à combinação de vários fatores, como: temperatura inadequada, período de exposição e estádio de desenvolvimento das flores (NOWAK e RUDNICKI, 1990). No entanto, pouco se conhece sobre a relação temperatura e tempo de exposição para a maioria das helicônias (JAROENKIT e PAULL, 2003), sendo necessária a caracterização dos sintomas de injúria por frio para determinação destes aspectos. Esse trabalho foi desenvolvido com o objetivo de descrever os sintomas de injúria por frio em diferentes espécies de helicônias.

\section{MATERIAL E MÉTODOS}

Hastes de $H$. wagneriana, Heliconia bihai, $H$.caribaea x H. bihai cv. Carib Flame foram colhidas da
Coleção de Germoplasma de Helicônias da Universidade Federal Rural de Pernambuco (UFRPE), localizada no município de Camaragibe (Aldeia km 13) - PE (756'33" $\mathrm{S}$ latitude, $35^{\circ} 01^{\prime} 50^{\prime}$ " W longitude e $100 \mathrm{~m}$ de altitude, temperatura média $24,1^{\circ} \mathrm{C}$ e precipitação média mensal de $171 \mathrm{~mm}$ ). As hastes florais foram coletadas com 3 brácteas abertas e transportadas para o Laboratório de Floricultura do Departamento de Agronomia/UFRPE.

Padronizou-se o corte das hastes florais com comprimento de $80 \mathrm{~cm}$ e elimiram-se as folhas acima das inflorescências, deixando cerca de $5 \mathrm{~cm}$ dos pecíolos das duas folhas mais próximas, com o objetivo de proteger as extremidades das brácteas de impactos durante o manuseio. Em seguida, as hastes florais foram submetidas a três tratamentos:

1 - colocadas em refrigerador tipo expositor, sob temperatura média de $2^{\circ} \mathrm{C}$, dentro de caixa de papelão (embalagem padrão para transporte com $1,00 \mathrm{~m}$ de comprimento x $0,35 \mathrm{~m}$ de largura $\mathrm{x} 0,25 \mathrm{~m}$ de altura);

2 - colocadas diretamente em refrigerador tipo expositor (sem caixa de papelão), sob temperatura média de $2^{\circ} \mathrm{C}$; e

3 - colocadas no ambiente de laboratório em recipientes contendo água (testemunha), sob temperatura de $25^{\circ} \mathrm{C}$ e umidade relativa (U.R.) de $60 \%$.

As hastes florais foram submetidas a $2^{\circ} \mathrm{C}$ com o objetivo de causar a injúria por frio para caracterização dos sintomas. Após 72 horas, as hastes florais foram retiradas do refrigerador expositor, cortadas na base (cerca de $3 \mathrm{~cm}$ ) e dispostas à temperatura ambiente em condição de laboratório, em recipientes com água - renovada a cada dois dias.

O delineamento experimental utilizado foi o inteiramente casualizado, com três tratamentos (refrigerador com caixa, refrigerador sem caixa e laboratório) e sete repetições na primeira avaliação, e cinco repetições na segunda avaliação. Em ambas as avaliações foram usadas $H$. bihai, $H$. wagneriana e $H$. caribaea $\mathrm{x} H$. bihai cv. Carib Flame.

Descreveram-se os sintomas da injúria por frio tão logo as hastes florais foram retiradas do refrigerador, a partir da comparação do aspecto visual das mesmas com a testemunha que foi mantida em condições de laboratório.

\section{RESULTADOS E DISCUSSÃO}

$\mathrm{O}$ aspecto visual dos sintomas da injúria por frio das hastes florais após 72 horas em refrigerador, com e sem caixa de papelão, e da testemunha mantida em condições de laboratório está apresentada nas figuras $1 \mathrm{e}$ 2 .

Ambos os tratamentos diferiram da testemunha (figura 1A), que apresentou como sintoma de senescência o ressecamento das extremidades das brácteas. Nas hastes florais colocadas no refrigerador sem caixa, foram constatadas manchas escuras nas brácteas, pecíolos das folhas e base das hastes murchas, evoluindo para manchas escuras no ponto de inserção das brácteas na ráquis e acentuada descoloração das pontas das brácteas (figura $1 \mathrm{~B}$ e B'). As hastes florais de $H$. wagneriana, colocadas no refrigerador dentro de caixa de papelão, apresentaram 
o murchamento dos pecíolos das folhas e da base da haste logo depois de retiradas. Observaram-se, posteriormente, manchas escuras na área de inserção das brácteas na ráquis e descoloração das pontas das brácteas (figura $1 \mathrm{C}$ e C'). Durante o período de avaliação das hastes florais mantidas sob refrigeração (tratamentos 1 e 2), as testemunhas não apresentaram sintomas semelhantes aos observados naquelas submetidas aos tratamentos, assegurando que os sintomas são de injúria por frio.

Os sintomas de senescência observados nas hastes florais da $H$. bihai (testemunha) foram semelhantes à testemunha da $H$. wagneriana (figura $2 \mathrm{~A}$ ). As hastes florais colocadas no refrigerador sem caixa de papelão apresentaram manchas escuras e base do pseudocaule murcha (figura 2B e B'). As hastes de $H$. bihai mantidas dentro de caixa de papelão no refrigerador, logo depois de retiradas apresentaram uma mancha clara na parte central das brácteas e murchamento dos pecíolos das folhas e da base da haste (figura $2 \mathrm{C}$ e C'). Os sintomas das hastes florais sem caixa de papelão evoluíram para sintomas semelhantes àqueles observados no tratamento das hastes colocadas dentro de caixa de papelão no refrigerador. Posteriormente verificaram-se manchas escuras na base das brácteas, no local da inserção da bráctea na ráquis, e ainda, uma evolução das manchas claras na parte central das brácteas para manchas de aspecto queimado. De acordo com WANG (1995) as alterações na membrana celular podem ser a principal causa da injuria por frio.

Nas hastes florais de $H$. caribaea $\times$ H. bihai cv. Carib Flame, após as 72 horas de acondicionamento dentro de caixa de papelão no refrigerador expositor, notaram-se manchas escuras nas brácteas, que se expandiram para a base das brácteas e para o local da inserção da bráctea na ráquis, verificaram-se também manchas de aspecto queimado na parte central das brácteas e, ainda, murchamento da base da haste e dos pecíolos das folhas. As hastes florais dispostas no refrigerador sem caixa apresentaram os mesmos sintomas daquelas do tratamento em refrigerador com caixa, ambas diferiram da testemunha, que não demonstrou sintomas evidentes de senescência.

Embora as hastes florais submetidas ao frio no refrigerador expositor sem caixa de papelão estivessem sujeitas à ventilação forçada, o que acarreta maior perda de umidade dos tecidos, foram verificados sintomas muito semelhantes aos das hastes florais colocadas dentro de caixa de papelão no refrigerador expositor (figuras $1 \mathrm{~B} \mathrm{e} \mathrm{C;} 2 \mathrm{~B}$ e C). Alguns dos sintomas observados por NOWAK \& RUDNICKI (1990) em flores e MORAES et al. (1999) em Strelitzia reginae, foram verificados também nesse trabalho, a exemplo de: murchamento de hastes, brácteas e pecíolos das folhas; descoloração das brácteas, acontecendo manchas de aspecto queimado, de coloração parda; e manchas escuras no local de inserção das brácteas na ráquis.

Apesar dos sintomas observados, nenhuma das espécies estudadas apresentou abscisão floral e perda de firmeza estrutural, características observadas por MATTIUZ et al. (2005) em H. psittacorum cv. Sassy mantidas nas temperaturas de $8^{\circ} \mathrm{C}$ e $10^{\circ} \mathrm{C}$.

\section{CONCLUSÃO}

Hastes florais de $H$. bihai, $H$. wagneriana e $H$. caribaea $\mathrm{x} H$. bihai $\mathrm{cv}$. Carib Flame quando submetidas à temperatura de $2{ }^{\circ} \mathrm{C}$, apresentaram sintomas de injúria por frio, como: descoloração do centro das brácteas com aspecto de queimado, manchas escurecidas na área de inserção das brácteas na ráquis e murchamento das extremidades dos pecíolos das folhas e da base das hastes. Estes sintomas não foram observados nas hastes mantidas em condição de laboratório, o que permite a afirmação de que os sintomas observados são de injúria por frio.

Os resultados preliminares servem de indicação para análise de injúria por frio em experimentos com helicônias, visando sua diferenciação entre os sintomas de senescência que ocorrem após a colheita.

\section{REFERÊNCIAS}

CASTRO, C. E. F. \& GRAZIANO, T. T. Espécies do gênero Heliconia (Heliconiaceae) no Brasil. Revista Brasileira de Horticultura Ornamental, Campinas, v.3, n.2. p.15-28, 1997.

CORBINEAU, F.El enfriamento de flores y plantas. Universidad de Pierre y Marie Curie, Paris y CNRS. Meudon, Francia, p. 62-90, 1992.

CRILEY, R.A.; BROSCHAT, T.K. Heliconia: botany and horticulaturae of new floral crop. Horticulturae Review, v.14, p.1-55, 1992.

FINGER, F.L.; VIEIRA,G. Controle de perda pós-colheita de água em produtos hortícolas. Ed UFV, 2002, p7-26.

JAROENKIT, T. \& PAULL, R. E. Postharvest handling of heliconia, red ginger, and bird-of-paradise. HortTechnology, 13 (2), p. 259-266, april-june 2003.

LAMAS, A. M. Floricultura tropical: técnicas de cultivo. Recife: SEBRAE/PE, 2001. 85p. (Empreendedor, 5).

MATTIUZ, C.F.M.; MATTIUZ, Ben-Hur; DURIGAN, M.F.B.; RODRIGUES, T.J.D.; BONACIN, G.A. Efeito do armazenamento refrigerado em inflorescências cortadas de Heliconia psittacorum 'Sassy'. Horticultura Brasileira. v.23, n.2, p.562, 2005.

MORAES, P. J.; CECON, P. R.; FINGRE, F. L.; BARBOSA, J. G.; ALVARES, V. S. Efeito da refrigeração e do acondicionamento em sacarose sobre a longevidade de inflorescências de Strelitzia reginae Ait. Revista Brasileira de Horticultura Ornamental, Campinas, v.5, n.2, p.151-156, 1999.

NOWAK, J. \& RUDNICKI, R. M. Postharvest handling and storage of cut flowers, florist greens and potted plants. Portland: Timber Press, 1990. 210p. 
SONEGO, G. \& BRACKMANN, A. Conservação póscolheita de flores. Ciência Rural, Santa Maria. v.25, n.3, p.473-479, 1995.

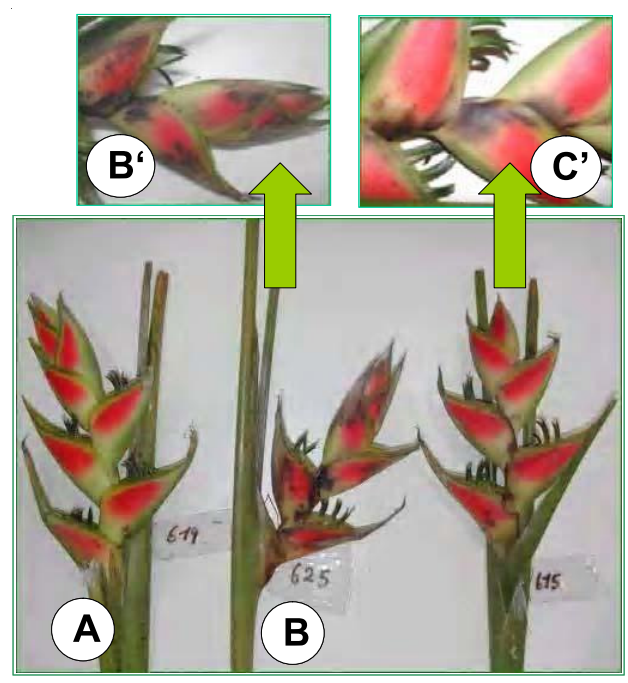

Figura 1: Hastes de Heliconia wagneriana. A: condição de laboratório;

B e B': refrigerador sem caixa e refrigerador com caixa; $\mathbf{C}$ e C': refrigerador com caixa.

Figure 1. Heliconia wagneriana stems A: laboratory environment

$B$ e $B^{\prime}$ : refrigerator without and with box $C$ e $C^{\prime}$ : refrigerator with box
WANG, C. Y. Effect of temperature preconditioning on catalase, peroxidase, and superoxide dismutase in chilled zucchini squash. Postharvest Biology and Technology, Amsterdam, v. 5, p. 67-76. 1995.

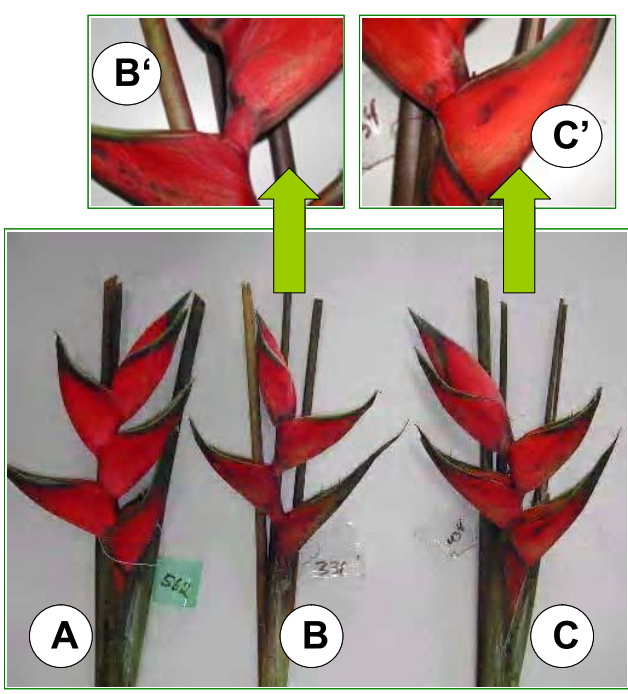

Figura 2: Hastes de Heliconia bihai. A: condição de laboratório; B e B': refrigerador sem caixa e refrigerador com caixa; C e C': refrigerador com caixa.

Figure 2. Heliconia bihai stems. A: laboratory environment $B$ e $B^{\prime}$ : refrigerator without and with box C e $C^{\prime}$ : refrigerator with box 